BMJ Open

Sport \&

Exercise

Medicine

\title{
The first prospective injury audit of League of Ireland footballers
}

\author{
Nigel Fitzharris, ${ }^{1}$ Gareth Jones, ${ }^{2}$ Ashley Jones, ${ }^{2}$ Peter Francis ${ }^{2}$
}

To cite: Fitzharris $\mathrm{N}$, Jones $\mathrm{G}$, Jones $\mathrm{A}$, et al. The first prospective injury audit of League of Ireland footballers. BMJ Open Sport Exerc Med 2017;3:e000220. doi:10.1136/bmjsem-2017000220

Accepted 4 August 2017

CrossMark

\section{${ }^{1}$ Department of Sport and Physical Activity, Edge Hill University, Ormskirk, UK ${ }^{2}$ Musculoskeletal Health Research Group, School of Clinical and Applied Science, Leeds Beckett University, Leeds, UK}

Correspondence to Dr Peter Francis; peter. francis@leedsbeckett.ac.uk

\section{ABSTRACT}

Objectives Football has the highest sports participation (10.6\%) in Ireland ahead of its Gaelic counterpart (3.9\%). Research into injury incidence and patterns in Irish football is non-existent. The aim of this study was to conduct a prospective injury audit of League of Ireland (semiprofessional) footballers during the 2014 season (8 months, 28 games).

Methods A total of 140 semiprofessional League of Ireland footballers were prospectively followed between March and November 2014. Data were collected in accordance with the international consensus on football injury epidemiology.

Results The injury rate was 9.2/1000 hour exposure to football $(95 \% \mathrm{Cl} 6.2$ to $12.9, \mathrm{p}<0.05)$. Players were at a higher risk of injury during a match compared with training $(23.1(95 \% \mathrm{Cl} 15.2$ to 31.3$)$ vs $4.8(95 \% \mathrm{Cl}$ 2.2 to 7.7$) / 1000$ hours, $p<0.05$ ). Injuries were most common during non-contact activity (54.6\%), mainly running (30.9\%), and occurred almost three times more often in the second half ( $56 \%$ vs $21 \%, p<05$ ). Strains $(50.1 \%)$ and sprains $(20.3 \%)$ were the most common injury types, and the thigh region was injured most often $(28.3 \%)$.

Conclusions The prevalence of injury in League of Ireland football is similar to that of European professional football, although the incidence of injury is higher. The incidence of injury is in line with that of Dutch amateur football.

\section{INTRODUCTION}

According to a report commissioned by the Irish Sports Council in 2013, football has the highest participation statistics (10.6\%) in Ireland ahead of its Gaelic counterpart $(3.9 \%)$. According to population trends, participation has doubled since 2008 $(5.2 \%) .{ }^{1}$ Despite these statistics, injury incidence and patterns in the highest level (League of Ireland, semiprofessional) of football played in Ireland has not been previously reported. Reducing injury incidence in most sports begins by gaining an understanding of the epidemiology of injury associated with that sport. ${ }^{2}$ Subsequently, therapeutic intervention can be evaluated. To date, the absence of any injury data collection from League of Ireland footballers has led to a reliance on

\section{What is known about this subject?}

- Injury prevalence in League of Ireland football is similar to professional football.

- Injury incidence in League of Ireland football is greater than in professional football and similar to that of high-level amateur footballers.

\section{What this study adds to existing knowledge?}

The knowledge that injury type is similar but injury rate is greater in semiprofessional football compared with professional football suggests that coaches and clinicians should focus on load.

research using cohorts of professional footballers to implement injury prevention strategies.

Recent studies on European cohorts of semiprofessional and professional football players have reported injury incidence between 5.6 and 14.2/1000 hours. ${ }^{3-5}$ Muscle strains are most common followed by sprains. ${ }^{6} 7$ Teams in northern Europe are said to have a higher injury incidence than teams in southern Europe. ${ }^{4}$ Within northern Europe, the Swedish league, which follows a 'summer soccer' season, has been reported to have a lower injury incidence than the Danish league, which follows a traditional autumn-spring season. ${ }^{7}$ Ireland, like Britain, is part of northern Europe and shares the same Marine west coast climate type. ${ }^{8}$ However, unlike Britain and majority of other northern European leagues, the League of Ireland has been operating as a 'summer soccer' league for over 10 years. A typical League of Ireland season runs between March and November each year. At present, the effects of 'summer soccer' in the League of Ireland on injury incidence and patterns compared with the traditional season of their nearest neighbours Britain and the rest of Europe are unknown. This research topic may be of particular 
importance, given that Britain remains the primary destination for many League of Ireland footballers. ${ }^{9}$ Furthermore, as the League of Ireland is ranked considerably lower (46th of 54) by the UEFA league ranking coefficients compared with nations reported previously in northern Europe who are in the top 50\% (Denmark, Sweden, Holland and England), it is unknown how injury statistics compare with elite level football.

During the 2014 season, the League of Ireland consisted of 12 premier division clubs and 8 division one clubs. The aim of this study was to report injury prevalence and incidence in League of Ireland footballers participating in the 2014 season for comparison with existing European cohorts.

\section{MATERIALS AND METHODS}

Following consultation with the Football Association of Ireland and an extensive literature search using the following databases: Medline, Science Direct, Sport Discus and PubMed, it was established that no previous studies have investigated injury prevalence among League of Ireland footballers. The study design was a prospective cohort study of injuries in League of Ireland footballers during one full season (28 games, March-November 2014). The study was conducted in accordance with the consensus statement on injury definitions and data collection procedures in football. ${ }^{10}$ Data were collected on a monthly basis from the individual club physiotherapists. After a complete explanation of the benefits, risks and requirements of the study, participants were invited to provide written informed consent. This study was approved by the research ethics committee of Edge Hill University.

\section{Study cohorts and inclusion}

The study cohort consisted of six of the eight teams in the League of Ireland first division (second tier). Players were not full-time professional and were engaged in work or education in addition to playing football. One team was excluded due to inadequate reporting of data, and another team chose not to partake in the study as the medical staff did not have time for the extra workload. All players belonging to the first team squads, who had signed contracts, were eligible for inclusion and agreed to participate. In total, 140 players (23 \pm 3 from each squad) were included in the study. The mean age was $23 \pm 4.7$ years.

\section{Definitions}

Injury was defined as any physical complaint sustained by a player that resulted from a football game or training session and led to them being unable to take a full part in future football training or match play. Injuries unrelated to football training sessions or games were not recorded. ${ }^{10}$
Injury severity was defined as the number of days that had elapsed from the date of injury to the date of the players return to full participation in training i. e. available for match selection. . Injuries were recorded as one of the following: slight (1-3 days absence), minor (4-7 days absence), moderate (8-28 days absence) or major (more than 28 days absence).

A recurrent injury was defined as an injury of the same type and at the same site as a previous injury. A recurrent injury can be categorised as early (within 2 months of the original injury), late occurrence(2 - 12 months after the original injury) or delayed occurrence (>12-months post injury)..$^{10}$

The location and the type of injury were defined using categories as outlined by Fuller et al. ${ }^{10}$

\section{Data collection}

Baseline player data and consent were collected at the time of player inclusion. During the season, the club physiotherapist registered individual player exposure in minutes during all first team club training sessions and matches. The club physiotherapist was also responsible for injury diagnosis and filled in an injury form for each injury. If an injured player had visited hospital or another clinic for injury assessment, these medical records were also reviewed by the club physiotherapist and added to the data set. Injury and attendance reports were sent to the lead author by the club physiotherapist one time per month. Data sets were available for all players in the squads examined except for one squad who were subsequently excluded due to inadequate reporting of data. The data were received from the gatekeeper and reviewed by the lead author. No further reliability analysis was completed.

\section{Statistical analyses}

Data were checked for normality of distribution by using the Komolgrov-Smirnov test and expressed as mean \pm SD for normally distributed variables and median (IQR) for non-normally distributed variables. Injuries are expressed as proportions (\% of total no. of injuries) and incidence per 1000 hours with a corresponding 95\% CI. All analyses were two sided, and the significance level was set at $\mathrm{p}<0.05$.

\section{RESULTS}

One hundred and fifty-two injuries were sustained in total, providing an injury incidence of 1.08 injuries per player. Forty-four players sustained at least one injury, providing an epidemiological incidence proportion for first injury of 0.314 (95\% CI 0.237 to 0.391 ). Thus, the average probability of sustaining at least one injury was $31.4 \%$ (95\% CI $23.7 \%$ to $39.1 \%$ ). Exposure and injury data for 140 League of Ireland football players are displayed in table 1. Players spend $75 \%$ of their exposure time in training but have an approximately fivefold risk of injury during a match. 


\begin{tabular}{ll}
$\begin{array}{l}\text { Table } 1 \text { Exposure and injury data in League of Ireland } \\
\text { football players }\end{array}$ & $\mathrm{n}$ \\
\hline $\begin{array}{l}\text { Exposure data } \\
\text { Season exposure, hours }\end{array}$ & 16528 \\
Season training exposure & 12584 \\
Season match exposure & 3944 \\
Overall injury data & 152 \\
\hline Total injuries, $\mathrm{n}$ & $9.2(95 \% \mathrm{Cl} 6.2$ to 12.9$)$ \\
\hline Injury incidence, total & $4.8(95 \% \mathrm{Cl} 2.2$ to 7.7$)$ \\
\hline $\begin{array}{l}\text { Injury incidence, training } \\
\text { Injury incidence, match play }\end{array}$ & $23.1(95 \% \mathrm{Cl} 15.2$ to 31.3$)$ \\
\hline
\end{tabular}

\section{Site of injury}

The thigh region was the most common (28.3\%, 95\% CI $15.8 \%$ to $39.4 \%$ ) site of injury, particularly the posterior compartment $(20.4 \%, 95 \%$ CI $18.7 \%$ to $22.0 \%)$. This was followed by the ankle $(20.4 \%, 95 \% \mathrm{CI}$ $14.3 \%$ to $25.7 \%)$ and the knee $(11.1 \%, 95 \%$ CI $8.3 \%$ to $16.2 \%)$. The top 3 sites of injury accounted for $59.7 \%$ of all injuries. A more detailed breakdown of injury site is illustrated in figure 1 .

\section{Type of injury}

Muscle strains accounted for over half $(50.1 \%$, 95\% CI $42.2 \%$ to $56.6 \%$ ) of all injuries, followed by sprains (20.3\%, 95\% CI $13.4 \%$ to $25.6 \%)$, contusions $(12.5 \%$, $95 \%$ CI $9.2 \%$ to $16.2 \%)$ and fractures $(5.3 \%$, 95\% CI $2.2 \%$ to $9.1 \%$ ). Figure 2 displays the 11 types of injury that occur and their relative percentage.

\section{Mechanism of injury}

Injuries were most common (54.6\%) during noncontact activity, mainly running $(30.9 \%$, 95\% CI $18.4 \%$ to $42.6 \%)$ but also twisting $(7.9 \%$, 95\% CI $2.0 \%$ to $11.6 \%$ ) and landing from a jump $(7.2 \%$,

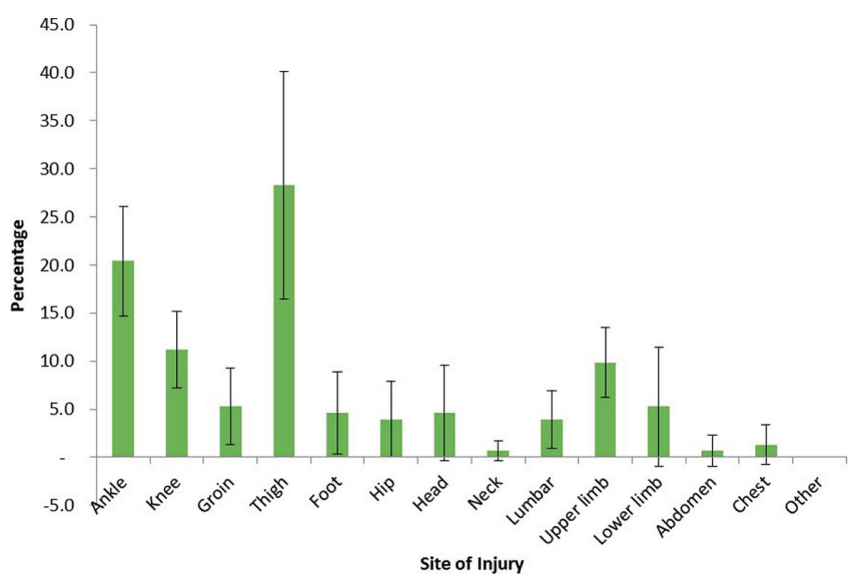

Figure 1 Injury location in League of Ireland football.
$95 \%$ CI $1.5 \%$ to $11.6 \%)$. Contact injuries accounted for $34.9 \%$ of all injuries, and these were attributed to player collision $(22.4 \%, 95 \%$ CI $15.0 \%$ to $35.6 \%)$ and tackling $(11.2 \%, 95 \% \mathrm{CI} \quad 4.0 \%$ to $17.4 \%)$. Overuse injuries accounted for $4.6 \%$ (95\% CI $2.6 \%$ to $8.3 \%$ ) of the injuries sustained. Sixteen per cent $(n=24)$ of all injuries were recurrent. A complete breakdown of injury mechanisms is illustrated in figure 3 .

\section{Time of injury}

Players were approximately three times more likely to be injured in the second half of a match compared with the first half. The period of the second half where players were most at risk was during the last $15 \mathrm{~min}$ of normal time $(28.9 \%, 95 \%$ CI $24.4 \%$ to $33.1 \%)$ and in the 15 min immediately after half-time $(23.0 \%, 95 \%$ CI $19.2 \%$ to $26.3 \%$ ). Injury occurrence relative to the stage of the match is displayed in figure 4 .

\section{Severity of injury}

The most common injuries sustained in both matches and training were moderate injuries, with major injuries least likely to occur (table 2).

\section{DISCUSSION}

This is the first study to report injury incidence and injury patterns in League of Ireland football. During the 2014 season, 152 injuries were recorded from six clubs, which provided a total injury incidence of 9.2/ 1000 hours. Moderate injuries occurred most often, and injuries were approximately five times more likely to occur during a match compared with training. The thigh region was most commonly injured followed by the ankle. Therefore, unsurprisingly, muscle strains and ligament sprains were the two most common injuries. League of Ireland injuries were more likely to occur in non-contact situations and during the final 15 min of the second half.

The overall injury incidence is higher than the northern (7.89/1000 hours), southern (7.02/ 1000 hours $)^{4}$ and combined (8.0/1000 hours) ${ }^{3}$ European region injury incidence for professional footballers. Our incidence rate is approximately that

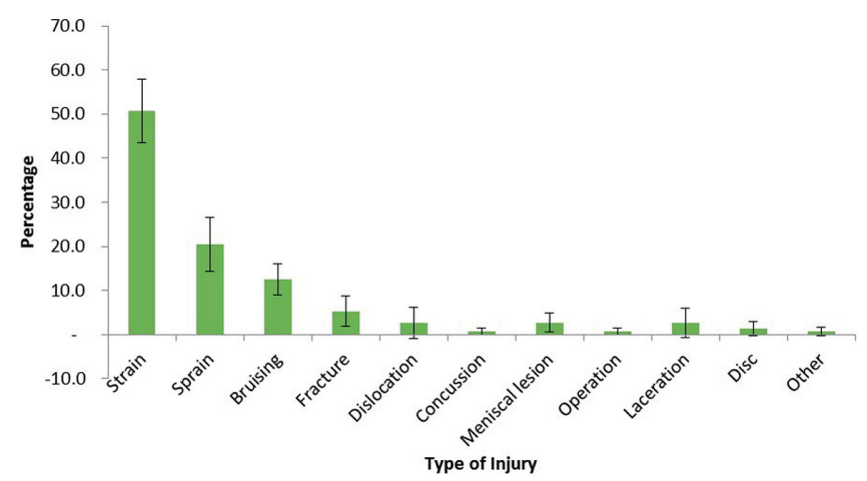

Figure 2 Type of injury in League of Ireland football. 


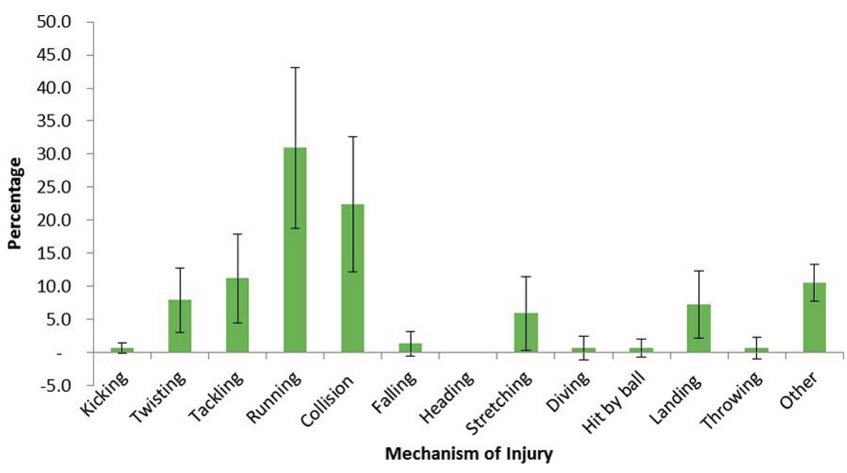

Figure 3 Mechanism of injury in League of Ireland football.

reported in 23 amateur Dutch squads (9.6/ 1000 hours). ${ }^{11}$ The same research group also highlighted a lower incidence rate (6.2 per 1000 hours) in professional Dutch footballers. ${ }^{5}$ The fact that semiprofessional footballers in Ireland have an injury incidence rate akin to amateurs in Holland may be due to Ireland's relatively low ranking in the UEFA club coefficients. Holland is ranked 13th of 54 compared with Ireland who is ranked 46th of 54 , and it may be that amateur players in Holland are akin to semiprofessional in Ireland. The similarities with amateur Dutch football do not appear to be consistent when compared with amateur players in Spain, ${ }^{12}$ Italy $^{13}$ and Sweden ${ }^{14}$ who demonstrate a heterogeneous but consistently lower training and match injury incidence. Differences are likely due to the definition of amateur. Although convenient to separate elite from amateur, the gradations in playing level in the amateur ranks are vast. The retrospective study of Spanish amateurs, ${ }^{12}$ although including a robust sample $(n=134570)$, includes players up to age 55 years who played in national but also regional leagues. Training $(0.49 / 1000$ hours) and match ( $1.15 / 1000$ hours) injury incidence were substantially lower compared with our cohort, and in contrast to our study, in which major injuries were lowest, major injuries accounted for almost half of all injuries in Spanish amateurs (47.4\%). This may suggest that amateurs of this level may play at a low enough intensity whereby less injuries occur, players play on through minor injuries (and therefore injuries go unrecorded) and more major injuries result as a result of a lower skill level or physical

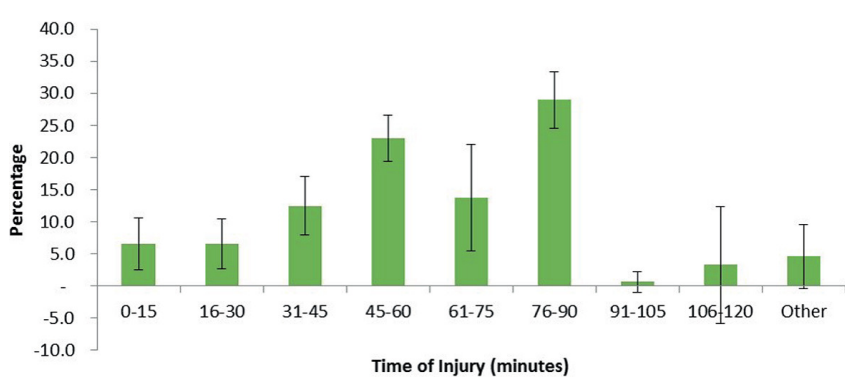

Figure 4 Time of injury in League of Ireland football.
Table 2 Injury severity in League of Ireland footballers.

\begin{tabular}{ll}
\hline Severity & n/1000 hours (\%) \\
\hline Slight (1-3 days) & $2.5(27.6)$ \\
Minor (4-7 days) & $2.3(25.7)$ \\
Moderate (8-28 days) & $3.3(36.2)$ \\
Major (>28 days) & $1.0(10.5)$
\end{tabular}

conditioning. It is also possible that the retrospective study design and the arbitrary assignment of exposure (one match, two training) lead to a lower injury incidence being reported. Amateurs restricted to those competing within the sixth tier of Swedish ${ }^{14}$ or Italian $^{13}$ football demonstrate a closer approximation in trends of training (2.0-2.7/1000 hours) and match injury (12.3-14.0/1000 hours) incidence but are still substantially lower. By contrast, the Dutch amateurs we have compared our data to are part of the second tier of Dutch amateur football and are likely of a higher skill level compared with the cohorts reported on from Spain, Sweden and Italy. It should be acknowledged that the studies from Holland, Sweden and Italy appear to follow the consensus guidelines for injury definition and classification used in our study but the Spanish study did not. This may add to the discrepancy seen in injury trends between the Spanish footballers and the other European amateurs.

The injury patterns in our study were akin to European professional footballers in that upper leg muscle strains were most common followed by ligament sprains. ${ }^{3}$ By contrast, the Spanish amateurs discussed above $^{12}$ reported ligament injury $(32.1 \%)$ and contusions (23.5\%) as occurring more often than muscle/ tendon injuries $(17.4 \%)$. It is plausible that less highintensity running, a willingness to play on through minor strains and a greater proportion of traumatic injuries due to a lack of physical conditioning may account for some of these differences. The amateurs in Swedish ${ }^{14}$ and Dutch ${ }^{11}$ football report muscle injuries to account for $48 \%$ and $37.9 \%$ of injuries, respectively, followed by ligament sprains accounting for $14 \%$ and $23.4 \%$ of injuries, respectively. Although the prevalence of injury in these studies follows the same order as ours, it does appear as though our proportions are more akin to professional football. It may be that the level of football in the League of Ireland sits somewhere in between Dutch amateur football and European professional football. The definition of amateur is an important consideration for future research in football. We have identified from the second highest tier of Irish football, which is considered semiprofessional, injury data which are in line with high-ranking amateurs in traditional football nations but very different to amateur footballers in its broadest sense. Definitions may be made easier to 
compare if all researchers work from the highest division (usually professional) downward when classifying leagues in order to give the reader a clearer sense of playing standard. The measurement of anthropometrical and physiological data may also prove useful toward this aim.

To the aim of comparing our injury data with that of Ireland's nearest and most climatically similar region, one study ${ }^{15}$ prospectively followed four English professional football clubs for 3 years and reported an injury incidence of 8.5/1000 hours. This may highlight demographic similarities between the regions. However, given the breadth and depth of evidence available from northern Europe, this suggestion is unlikely, and the rates reported are more likely linked to playing standards. To the best of the authors knowledge, there is only one other study ${ }^{7}$ highlighting injury incidence from teams in northern Europe using the summer soccer season format. Our incidence is higher than that reported in professional footballers from the Swedish first division (9.2 vs 7.65/1000 hours). This provides further support for the hypothesis that differences in injury incidence emerge from playing standard rather than season format. Sweden, like Holland, are also ranked considerably higher (18th of 54) than Ireland in the UEFA coefficient rankings. The reasons for a greater injury incidence at lower levels are suggested to be linked to less high-quality medical staff being available, lower quality or less time for rehabilitation, physiological differences ${ }^{16}$ and a smaller competitive squad to rely on. ${ }^{6}{ }^{17}$ A smaller competitive squad has greater potential for those with minor injuries to play and suffer a moderate or major injury. ${ }^{6}$

League of Ireland players were approximately five times more likely to receive an injury during a match compared with training, which is in keeping with the 3.5-8 times greater risk associated with match play across Europe. ${ }^{3} 415$ The predominate cause of this ratio is thought to be match intensity. ${ }^{18}$ In keeping with previous literature, we report muscle strains to account for half of all injuries and the thigh region, especially the posterior compartment, to be particularly affected. ${ }^{5} 1920$ This finding provides further support to recent data which suggest that although the incidence of ligament injury has reduced, muscle injury remains unchanged. ${ }^{2}$ The ankle region was the second most frequent site of injury, and perhaps unsurprisingly, ligament sprains were the second most prevalent injury. Injuries occurred most often during non-contact activity, mainly running, which is the primary activity whereby muscle injuries occur. ${ }^{21}$ Injuries were three times more likely to occur in the second half. Unlike previous literature which suggests injuries occur most often in the final $15 \mathrm{~min}$ of each half, we only report this phenomena to occur in the second half. The next 'high-risk' time period for injury occurrence in this study was the first $15 \mathrm{~min}$ after half-time. In contrast to the overall prevalence of injury in this study, ankle sprains were most common (29\%) followed by hamstring strains (18\%) during this period. Although injuries occurring in the final stages of the second half fit with the fatigue hypothesis, ${ }^{22-24}$ our findings in the first $15 \mathrm{~min}$ of the second half may suggest inadequate warm-up after the half-time break. Weston $e t a l^{25}$ reported a reduction $\left(-1.5^{\circ} \mathrm{C}\right.$ to $\left.2.0^{\circ} \mathrm{C}\right)$ in muscle temperature during the half-time break. Furthermore, Salgado et $a l^{26}$ and Mohr et $a l^{27}$ have reported improvements in joint position sense and sprint performance following a warm-up in footballers. However, as intensive warm-ups are not common place after half-time, even in professional football, our findings may be coincidental, and so our interpretation remains speculative.

In League of Ireland footballers, moderate injuries (8-28 days) occurred most often, followed by minor, slight and then major injuries, which is in agreement with previous literature from northern Europe ${ }^{4}$ and England. ${ }^{15}$ A large-scale study ${ }^{17}$ on top-level and elite European $(n=8970)$ footballers suggested a more even distribution of injury among slight, minor, moderate and major injuries. This may be due to a more representative European sample but also, as discussed above, could be contributed to by more informed clinical decision making and a larger competitive squad at the elite level. ${ }^{28}$ Linked to this and in line with the greater injury incidence reported in our study, recurrent injury was also greater (16\% vs $12 \%$ ) than that reported by Ekstrand $e t a l^{3}$ in professional European footballers. As previous injury is a significant risk factor for future injury, these findings are somewhat unsurprising. ${ }^{29}$ It is also possible that in smaller squads, there is a greater risk of returning a player to play too soon and subjecting the player to a sudden change in loading, which is associated with a dramatic increase in injury risk. ${ }^{21}$ Furthermore, the time loss due to injury for our players may have been greater due to the impact that non-football-related professional or educational commitments may have had on recovery time.

\section{Methodological considerations}

This is the first study to collect injury data in League of Ireland football. Predefined protocols for collecting and reporting data on football injuries were followed, which will allow interstudy comparisons of future studies involving League of Ireland footballers. However, the quality of the data reported was dependent on the goodwill of the club physiotherapists who volunteered to participate. There were multiple physiotherapists reporting injury data in this study, which may have reduced inter-rater reliability of the data. Furthermore, match data were verified against match reports on official websites rather than in person. It is possible that the two clubs who did not participate may have had apprehension about the release of data. For this reason, future studies should try to engage the 
national governing body in order to access all clubs particularly in the premier division.

Despite capturing the majority of the league participants, the sample was small $(n=140)$ and the audit of injuries was only conducted over one season. Furthermore, although we have attempted to explain some of the potential reasons for our findings, no causal relationships can be established from what is a descriptive rather than mechanistic study. The study findings and comparisons to existing literature must be interpreted cognisant of the difficulty in accounting for player level. The League of Ireland is ranked 46th of the 54 member states and has yet to have its players physiological, biomechanical and psychological characteristics fully described. In addition, the difference in injury incidence and patterns between the premier and the first division within the League of Ireland is also unknown, and therefore comparison with the rest of Europe remains difficult. Future studies should seek to characterise the injury incidence in the 12 squads participating in the League of Ireland Premier Division.

\section{Perspectives}

Our study used epidemiological study procedures that have international consensus and are recommended by UEFA and FIFA to report injury incidence in a previously unreported UEFA member state. ${ }^{10}$ Other than Sweden, no other northern European league using a summer soccer season format has been surveyed. Furthermore, the study surveyed injury data from $75 \%$ of the League of Ireland squads participating in division 1 (second tier) and therefore can be considered a representative sample. Our findings suggest that injury incidence and injury patterns in League of Ireland football players are higher than that experienced by other European professional players and support the hypothesis that differences in injury incidence emerges from playing standard rather season format. In keeping with previous literature, we reported muscle strains to account for half of all injuries sustained and the posterior compartment of the thigh to be most prevalent. Of note, there was a tendency towards injury occurrence in the first $15 \mathrm{~min}$ after the half-time break, which may in part be explained by inadequate warm-up procedures used by League of Ireland footballers.

Acknowledgements The authors would like to thank the League of Ireland club physiotherapists for their assistance in data collection. The authors would also like to acknowledge Rachel Moran and David Rhodes for their assistance with supervision of the project.

Contributors NF collected and analysed the data. PF wrote the manuscript. GJ conducted further data analysis. AJ reviewed and edited the manuscript.

Competing interests None declared.

Ethics approval Edge Hill University.

Provenance and peer review Not commissioned; externally peer reviewed.
Data sharing statement Research materials related to the paper including data can be accessed by contacting the corresponding author (PF).

Open Access This is an Open Access article distributed in accordance with the Creative Commons Attribution Non Commercial (CC BY-NC 4.0) license, which permits others to distribute, remix, adapt, build upon this work noncommercially, and license their derivative works on different terms, provided the original work is properly cited and the use is non-commercial. See: http:// creativecommons.org/licenses/by-nc/4.0/

(C) Article author(s) (or their employer(s) unless otherwise stated in the text of the article) 2017. All rights reserved. No commercial use is permitted unless otherwise expressly granted.

\section{REFERENCES}

1. Ipsos M, Council IS. The Irish sports monitor 2013 annual report, 2013.

2. Ekstrand J, Hägglund $\mathrm{M}$, Kristenson $\mathrm{K}$, et al. Fewer ligament injuries but no preventive effect on muscle injuries and severe injuries: an 11-year follow-up of the UEFA Champions League injury study. $\mathrm{Br} \mathrm{J}$ Sports Med 2013;47:732-7.

3. Ekstrand J, Hägglund M, Waldén M. Injury incidence and injury patterns in professional football: the UEFA injury study. Br J Sports Med 2011;45:553-8. bjsports60582.

4. Waldén $\mathrm{M}$, Hägglund $\mathrm{M}$, Orchard J, et al. Regional differences in injury incidence in European professional football. Scand J Med Sci Sports 2013;23:424-30.

5. Stubbe $\mathrm{JH}$, van Beijsterveldt AM, van der Knaap S, et al. Injuries in professional male soccer players in the Netherlands: a prospective cohort study. J Athl Train 2015;50:211-6.

6. Hawkins RD, Hulse MA, Wilkinson C, et al. The association football medical research programme: an audit of injuries in professional football. Br J Sports Med 2001;35:43-7.

7. Hägglund $M$, Waldén $M$, Ekstrand J. Injury incidence and distribution in elite football-a prospective study of the Danish and the Swedish top divisions. Scand J Med Sci Sports 2005;15:21-8.

8. Kottek M, Grieser J, Beck C, et al. World Map of the Köppen-Geiger climate classification updated. Meteorologische Zeitschrift 2006;15:259-63.

9. Curran C. Irish-born players in England's Football Leagues, 1945-2010: an historical and geographical assessment. Sport Soc 2016;19:74-94.

10. Fuller CW, Ekstrand J, Junge $A$, et al. Consensus statement on injury definitions and data collection procedures in studies of football (soccer) injuries. Clin J Sport Med 2006;16:97-106.

11. van Beijsterveldt AM, Stubbe JH, Schmikli SL, et al. Differences in injury risk and characteristics between Dutch amateur and professional soccer players. J Sci Med Sport 2015;18:145-9.

12. Herrero H, Salinero JJ, Del Coso J. Injuries among Spanish male amateur soccer players: a retrospective population study. Am $J$ Sports Med 2014;42:78-85.

13. Gatterer $\mathrm{H}$, Ruedl $\mathrm{G}$, Faulhaber $\mathrm{M}$, et al. Effects of the performance level and the FIFA "11" injury prevention program on the injury rate in Italian male amateur soccer players. J Sports Med Phys Fitness 2012;52:80-4.

14. Hägglund $M$, Waldén $M$, Ekstrand $J$. Lower reinjury rate with a coach-controlled rehabilitation program in amateur male soccer: a randomized controlled trial. Am J Sports Med 2007;35:1433-42.

15. Hawkins RD, Fuller CW. A prospective epidemiological study of injuries in four English professional football clubs. Br J Sports Med 1999;33:196-203.

16. Emmonds S, Till K, Jones B, et al. Anthropometric, speed and endurance characteristics of English academy soccer players: do they influence obtaining a professional contract at 18 years of age? Int J Sports Sci Coach 2016;11:212-8.

17. Hägglund $M$, Waldén $M$, Ekstrand $J$. Injury recurrence is lower at the highest professional football level than at national and amateur levels: does sports medicine and sports physiotherapy deliver? Br. J. Sports Med 2016. bjsports-2015-095951.

18. Ekstrand J, Timpka T, Hägglund M. Risk of injury in elite football played on artificial turf versus natural grass: a prospective twocohort study. Br J Sports Med 2006;40:975-80.

19. Noya Salces J, Gomez-Carmona PM, Moliner-Urdiales D, et al. An examination of injuries in Spanish Professional Soccer League. $J$ Sports Med Phys Fitness 2014;54:765-71.

20. Mallo J, González P, Veiga S, et al. Injury incidence in a spanish subelite professional football team: a prospective study during four consecutive seasons. J Sports Sci Med 2011;10:731-6.

21. Gabbett TJ. The training-injury prevention paradox: should athletes be training smarter and harder? Br J Sports Med 2016;50:273-80. 
22. Rahnama N, Reilly T, Lees A. Injury risk associated with playing actions during competitive soccer. Br J Sports Med 2002;36:354-9.

23. Mohr M, Krustrup P, Bangsbo J. Match performance of highstandard soccer players with special reference to development of fatigue. J Sports Sci 2003;21:519-28.

24. Rampinini E, Impellizzeri FM, Castagna C, et al. Technical performance during soccer matches of the Italian Serie A league: effect of fatigue and competitive level. J Sci Med Sport 2009;12:227-33.

25. Weston M, Batterham AM, Castagna C, et al. Reduction in physical match performance at the start of the second half in elite soccer. Int J Sports Physiol Perform 2011;6:174-82.
26. Salgado E, Ribeiro F, Oliveira J. Joint-position sense is altered by football pre-participation warm-up exercise and match induced fatigue. Knee 2015;22:243-8.

27. Mohr M, Krustrup P, Nybo L, et al. Muscle temperature and sprint performance during soccer matches-beneficial effect of re-warmup at half-time. Scand J Med Sci Sports 2004;14:156-62.

28. Hägglund $M$, Waldén $M$, Ekstrand J. Injury recurrence is lower at the highest professional football level than at national and amateur levels: does sports medicine and sports physiotherapy deliver? $\mathrm{Br} \mathrm{J}$ Sports Med 2016:50:751-8.

29. Hägglund $M$, Waldén $M$, Ekstrand J. Previous injury as a risk factor for injury in elite football: a prospective study over two consecutive seasons. Br J Sports Med 2006;40:767-72. 